\title{
红砂根系分叉数和分支角度权衡关系的坡向差异
}

\author{
郑慧玲 赵成章 ${ }^{*}$ 徐 婷 段贝贝 韩 玲 冯 威
}

西北师范大学地理与环境科学学院, 甘肃省湿地资源保护与产业发展工程研究中心, 兰州 730070

摘 要 根系构型是决定根系分布及其对土体搜索效率的重要因素, 是植物与资源环境异质性相互适应的结果。利用ArcGIS 建立研究区域的数字高程模型(digital elevation model), 采用全根系挖掘法, 研究了祁连山北坡荒漠草原不同坡向红砂 (Reaumuria songarica)根系分叉数和分支角度的关系。结果表明: 不同坡向梯度草地群落的盖度、密度、高度和土壤含水量 呈不同的变化趋势 $(p<0.05)$, 红砂种群的密度、高度和根冠比等生物学特征的变化规律存在差异 $(p<0.05)$; 不同坡向红砂根 系分叉数和分支角度的相关性存在差异 $(p<0.05)$, 在南坡和北坡红砂根系分叉数和分支角度之间存在极显著的负相关关系 $(p<0.01)$, 在东坡和西坡根系分叉数和分支角度之间存在显著的负相关关系 $(p<0.05)$, 红砂根系分配给根系分叉数和分支角 度的资源存在着“此消彼长”的权衡关系; 随着坡向由南坡向西坡、东坡、北坡转变, 红砂根系分叉数和分支角度回归方程的 标准化主轴斜率逐渐减小 $(p<0.05)$, 红砂根系构型模式由扩散型转向聚集型。不同坡向红砂根系合理权衡连接长度和分支角 度的资源配置模式，反映了异质生境中植物种群应对资源多重竞争的环境生态适应机制。

关键词 红砂，根系构型，根系分叉数，根系分支角度，坡向

引用格式: 郑慧玲, 赵成章, 徐婷, 段贝贝, 韩玲, 冯威 (2015). 红砂根系分叉数和分支角度权衡关系的坡向差异. 植物生态学报, 39, 1062-1070. doi: 10.17521/cjpe.2015.0103

\section{Trade-off relationship between root forks and branch angle of Reaumuria songarica on dif- ferent aspects of slopes}

ZHENG Hui-Ling, ZHAO Cheng-Zhang*, XU Ting, DUAN Bei-Bei, HAN Ling, and FENG Wei

College of Geography and Environmental Science, Northwest Normal University, Research Center of Wetland Resources Protection and Industrial Development Engineering of Gansu Province, Lanzhou 730070, China

\section{Abstract}

Aims Root architecture is a major determinant in root spatial distribution and soil searching efficiency, may reflect plant strategies to adapt to the environments. Our objective was to examine the relationship between root forks and branch angle of Reaumuria songarica in response to slope aspects in the northwest of China.

Methods The study site was located in desert grasslands on the northern slope of Qilian Mountains, Gansu Province, China. Survey and sampling were carried out along 20 belt transects. It were set up on sites of four different slope aspects at intervals of $30 \mathrm{~m}$ vertically from elevation $1940 \mathrm{~m}$ of the study area moving upward, 6 plots were set up flatly on site of each belt transect at intervals of $20 \mathrm{~m}$. A handheld GPS was used to record longitude, latitude and altitude of each plot. ArcGIS was used to set up digital elevation model to extract the information of elevation, aspect, and slope for each plot. The traits of plant communities were investigated and 1 individual's samplings of $R$. songarica were used to measure the root forks, root length and root branch angle in laboratory in each plot, and biomass of different organs was measured after being dried at $80{ }^{\circ} \mathrm{C}$ in an oven. The 120 plots were categorized into groups of south, west, east, and north aspects of slopes, and the linear regression analysis was then used to examine the trade-off relationship between root forks and branch angle in various groups.

Important findings The results showed that with the slope aspect turned from south, west, east to north, the density, cover, height, above biomass and soil moisture content of the plant community displayed a pattern of initial increase, while the height, root-shoot ratio, root branch angle of $R$. songarica displayed a pattern of initial decrease, and the density, specific root length, root forks increase. The number of root forks was negatively associated with the branch angle, but the relationship varied along the aspect gradient $(p<0.05)$. There was a highly

收稿日期Received: 2015-06-21 接受日期Accepted: 2015-09-20

* 通讯作者Author for correspondence (E-mail: zhaocz601@163.com) 
significant negative correlation $(p<0.01)$ between the root forks and branch angle on north slope and south slope, whereas less significant $(p<0.05)$ on the east slope and west slope. There is a trade-off relationship between the root forks and link length. In addition, when the slope aspect changed from south to west, east and north, the standardized major axis slope of regression equation in the scaling relationships between root forks and branch angle decrease $(p<0.05)$, indicating that the root architecture model of $R$. songarica by diffusion to gather. Consequently, the patterns of resource allocation between root forks and branch angle in different slope habitats reflected the mechanism of environment adaptation under conditions of multiple competitions for resources in plant populations.

Key words Reaumuria songarica, root architecture, root forks, root branch angle, aspect

Citation: Zheng HL, Zhao CZ, Xu T, Duan BB, Han L, Feng W (2015). Trade-off relationship between root forks and branch angle of Reaumuria songarica on different aspects of slopes. Chinese Journal of Plant Ecology, 39, 1062-1070. doi: 10.17521/cjpe. 2015.0103

植物根系作为植被与土壤之间物质、能量交换 的主要通道(黄晶晶, 2013), 在植物水分和养分吸 收、运移过程中有着不可替代的作用(Kong et al., 2014), 影响着地上部分以及整个植株的生长和发 育, 其中根系的分支状况和构型对营养物质的吸收 起着关键作用(Dannowski \& Block, 2005)。根系构型 是植物与环境异质性资源相互适应的结果(Malamy, 2005), 其对环境的适应是通过根系分支结构、空间 分布格局等构型特征的改变表现出来的(Tracy et al., 2015)。为了应对地理环境和资源供给水平造成 的胁迫和干扰, 植物根系会根据所处生境的资源条 件适时调整和转化根系分叉数和分支角度等构型特 征, 实现植物功能性状间的资源权衡(陈荣婷和许 振柱, 2014)。根系分叉数影响植物根系对资源物质 的受食能力和植株的固定作用(孙浩燕等, 2014), 根 系分支角度与根系的分布范围和拓展能力紧密相关 (黄晶晶, 2013), 二者在很大程度上决定了根系在土 壤中的位置和对土体的受养效率(Malamy, 2005), 反映了不同生境中植物根系在物质吸收、利用和循 环中的作用。地形作为生境条件的综合指示, 控制 水热因子的重新分配, 修饰植被空间分布格局, 此 自然法则具有普适性(常学礼等, 2015)。坡向是地形 重要的影响因素之一, 影响了太阳辐射和降水的空 间再分配, 往往导致局部小气候的产生(Cantón et al., 2004), 从而改变光照、温度及土壤水分的分布, 导致群落环境和植物的生存条件产生差异(侯兆疆 等, 2014), 进而改变植物碳资源分配格局和根系构 型构建策略(Oppelt et al., 2001)。为了提高植株生存 适合度和竞争能力, 植物根系通过分支角度和分叉 数等性状的响应, 促使根系构型模式进行适应性调
整, 构建与环境梯度相匹配的根系营养吸收和传输 系统。因此, 从不同坡向资源条件变化的角度研究 植物根系构型的空间分异格局和资源配置模式，对 于理解植物在异质生境中的环境适应机制具有重要 的理论意义。

红砂(Reaumuria songarica) 是一种广泛分布于 我国西北荒漠地区的柽柳科小灌木, 是荒漠植被的 常见建群种和优势种, 具有极强的抗干旱能力。在 全球变化背景下, 红砂等荒漠植物面对日益严酷的 环境压力, 需要不断调整主要功能性状构建的资源 策略, 适时改变植物碳资源分配格局和根系构型构 建策略(单立山等, 2013), 这对维持荒漠生态系统的 稳定性具有重要意义。目前, 许多学者围绕植物根 系分支模式的竞争能力(Glimskär, 2000)、根系构型 的拓扑结构(马新明等, 2006)、多枝柽柳(Tamarix ramosissima) 和骆驼刺(Alhagi sparsifolia)幼苗生物 量分配及根系分布特征(曾凡江等, 2010)、不同树种 间细根结构和形态特征(熊德成等, 2012)、骆驼刺群 落在干旱生境下细根生产与周转(冀卫萍等, 2013)、 植物根系构型的生态适应性(杜建会等, 2014)以及 根系功能性状的可塑性与空间异质性(Druille et al., 2015)等方面对植物根系构型进行了系统研究, 但 是有关生境梯度下植物根系构型构建的资源配置权 衡机制等研究仍显不足, 限制了对异质生境中植物 表型可塑性机制的解析。本文通过研究祁连山北坡 荒漠草地红砂根系分叉数和分支角度的分布格局, 试图解析：(1)不同坡向红砂根系分叉数和分支角度 的变化规律; (2)造成红砂根系分叉数和分支角度异 速生长关系的原因, 旨在从植物根系功能性状建成 的角度阐明红砂种群的环境适应性规律, 为进一步 
了解荒漠植物的表型可塑性机制提供理论依据。

\section{1 材料和方法}

\section{1 研究区域和样地概况}

研究区位于祁连山北坡中山区的甘肃省肃南县 㿝矾沟地区, 属于山地荒漠草原, 地理位置为 $38.91^{\circ}-38.98^{\circ} \mathrm{N}, 99.81^{\circ}-99.87^{\circ} \mathrm{E}$, 海拔1 834-2 118 $\mathrm{m}$, 年平均气温 6-7 ${ }^{\circ} \mathrm{C}, \geqslant 0{ }^{\circ} \mathrm{C}$ 积温为 2 933-3 300 ${ }^{\circ} \mathrm{C}$, 年降水量 $173.1 \mathrm{~mm}$, 年蒸发量2 $013.7 \mathrm{~mm}$, 是 年降水量的11.6倍。土壤为山地灰漠土, 由于气候干 燥和长期剥蚀的作用, 形成砾石倾斜和裸岩广布的 低山地貌景观。植物以旱生小半灌木为主, 红砂属 (Reaumuria)植物占相当比例。主要植物有红砂、合 头草(Sympegma regelii)、驼线黎(Krascheninnikovia ceratoides)、盐爪爪(Kalidium foliatum)、珍珠猪毛菜 (Salsola passerina)、霸王(Zygophyllum xanthoxylon), 伴生植物有灌木亚菊(Ajania fruticulosa)、中亚紫苑 木(Asterothamnus centraliasiaticus)、碱韭 (Allium polyrhizum)、黄花瓦松(Orostachys spinosus)、黄花 补血草(Limonium aureum)、三芒草(Aristida adscensionis)等。供试草地为灌木和旱生草本的混生群 落。受干旱气候的影响, 南坡植被稀疏、生长状况 差, 北坡植被郁闭度较高。

\section{2 实验设置}

在地形图上将研究区划分为 4 个坡向, 每个坡 向沿垂直海拔梯度(1 940-2 $115 \mathrm{~m}$ )间隔30 m布置1 条长 $140 \mathrm{~m}$ 、宽 $10 \mathrm{~m}$ 的水平样带, 总计 20 条水平样 带。在多次现场踏勘的基础上, 在每条水平样带上 间隔 $20 \mathrm{~m}$ 设置 1 个 $5 \mathrm{~m} \times 5 \mathrm{~m}$ 的样方, 共计 120 个样 方, GPS测量每个样方的经纬度和海拔。第一, 进行 草地群落学特征调查, 测定样方内所有植物的盖 度、高度、密度和地上生物量。第二, 每一样方内 随机选择 1 株生长良好的红砂, 每个坡向共计 30 株 红砂用于测定植株的生物量和根系性状, 首先将每 株红砂的地上枝条刈割并装入自封袋, 然后采用壕 沟法和根系跟踪相结合的方法挖掘整株根系, 在离 植株 $2 \mathrm{~m}$ 处挖一条 $2 \mathrm{~m} \times 0.6 \mathrm{~m} \times 1.6 \mathrm{~m}$ 壕沟, 然后利 用小铁铲慢慢清除植株周围的泥沙到壕沟并不断清 理沟中层积的沙土, 直至直径 $>3 \mathrm{~mm}$ 的整株根系完 全暴露, 因为直径 $<3 \mathrm{~mm}$ 根系构型的重建在研究中 很难实现(Oppelt et al., 2000, 2005), 尽量保持根系 在自然空间中的位置。根系完全暴露后, 采用 $50 \mathrm{~cm}$ $\times 50 \mathrm{~cm}$ 的网格确定根系的分布位置(直到没有根系 出现为止), 按照1:50的比例在 $35 \mathrm{~cm} \times 25 \mathrm{~cm}$ 的坐标 纸上准确绘制根系构型图, 然后把植株根系装入尼 龙袋带回实验室。在室内将根系置于细笁之上用水 冲洗，同时去除其他杂质，仅留下红砂的根系; 用 游标卡尺、卷尺和量角器等工具, 分别测定所有样 点红砂的根长、分叉数和分支夹角 $\left(^{\circ}\right)$; 之后把植株 根系和地上部分分别装入信封, 在 $80{ }^{\circ} \mathrm{C}$ 烘箱里烘 24 $\mathrm{h}$ 后用电子天平 $(0.0001 \mathrm{~g})$ 称质量并记录。第三, 进 行土壤水分采样, 每个样方内随机选取 3 个样点, 用 土钻(直径 $4 \mathrm{~cm}$ )采集0-100 cm 土层范围分5层间隔 $20 \mathrm{~cm}$ 取土壤样品, 钻取的土壤先按土层分取, 之后 将各层土壤进行混合, 重复3次, 剔除样品中明显的 植物根段和枯落物等杂质, 装入编号的铝盒中, 带 回实验室, 在 $105{ }^{\circ} \mathrm{C}$ 的烘箱内烘 $12 \mathrm{~h}$ 取出称质量, 计 算出各样地 $0-100 \mathrm{~cm}$ 土层土壤质量含水量。

\section{3 空间数据采集}

利用ArcGIS对研究区 $1: 5$ 万地形图进行数字化, 得到研究区域 $10 \mathrm{~m}$ 分辨率的数字高程模型(DEM)。 在DEM基础上利用Spatial Analyst模块中的Surface Analysis命令提取坡向, 它表示地表面上一点的切 平面的法线矢量 $n$ 在水平面的投影 $n_{x o y}$ 与过该点的正 北方向的夹角, 其中坡向组别以国际划分法确定 (陈瑶等, 2006), 具体方法参见汤国安等(2010) 文献。

\section{4 数据处理}

将坡向划分为北坡 $\left(315^{\circ}-360^{\circ}\right.$ 和 $\left.0^{\circ}-45^{\circ}\right)$ 、东坡 $\left(45^{\circ}-135^{\circ}\right)$ 、南坡 $\left(135^{\circ}-225^{\circ}\right)$ 和西坡 $\left(225^{\circ}-315^{\circ}\right) 4$ 个 坡向组。根据游标卡尺、卷尺和量角器等工具测定 获得的根长、分叉数和分支角度等, 计算出各坡向 红砂根系的比根长。比根长表示单位生物量的细根 长度, 它们反映投入到根系的生物量中用于吸收养 分的效率，其值越大，表明投入相同的成本有越高 的养分利用效率(Bauhus et al., 2000)。计算公式为: 比根长 $\left(\mathrm{cm} \cdot \mathrm{g}^{-1}\right)=$ 根长 $(\mathrm{cm})$ /生物量 $(\mathrm{g})$ 。根系分叉数和 分支角度数据分析主要采用标准化主轴估计(SMA) 的方法(Warton et al., 2006), 由软件(S)MATR Version 2.0 (Falster et al., 2006)计算完成。对每个样方 红砂根系分叉数和分支角度进行对数 (以10为底) 转 换后再进行分析, 对数转换使之符合正态分布。采 用 $y=a x^{b}$, 线性转换成 $\log (y)=\log (a)+b \log (x)$, 式 中 $x$ 和 $y$ 表示两个特征参数, $b$ 为斜率, 即异速生长参 
数或相对生长的指数, 当 $|b|=1$ 时, 表示两者是等速 变化关系; 当 $|b|$ 显著偏离 1 时, 两者间为异速变化 关系(Harvey \& Pagel, 1991)。实验所用数据采用 SPSS 16.0软件进行处理分析, 用SigmaPlot 10.0和 Excel软件绘图。

\section{2 结果分析}

\section{1 不同坡向红砂根系分叉数与分支角度的变化}

单因素方差分析表明, 不同坡向草地红砂的根 系分叉数与分支角度均存在显著差异 $(p<0.05$, 图 1)。随着坡向由南坡转向西坡、东坡和北坡, 红砂 根系分叉数呈逐渐增加趋势, 从南坡的15.34个增加 至北坡的31.17个，增加了1.03倍; 而红砂根系分支 角度呈相反的变化趋势, 从南坡的 $86^{\circ}$ 减小至北坡 的 $62^{\circ}$, 减小了 $28 \%$ 。

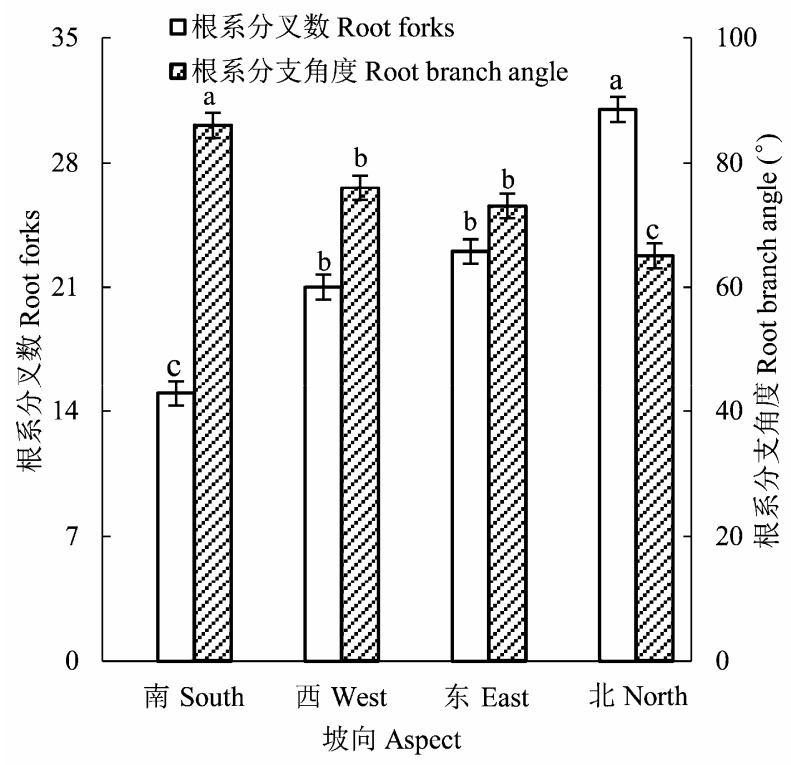

图1 红砂根系分叉数和分支角度沿坡向梯度的变化(平均 值土标准误差)。不同小写字母表示坡向间差异显著 $(p<$ 0.05)。

Fig. 1 Changes in root forks and branch angle of Reaumuria songarica along the aspect gradient (mean $\pm S E$ ). Different lowercase letters indicate significant differences among slope aspects $(p<0.05)$.

\section{2 不同坡向红砂根系分叉数与分支角度之间的} 关系

Pearson相关性分析表明，南坡和北坡甘肃红砂 根系分叉数和分支角度均存在极显著负相关 $(p<$ $0.01)$, 而东坡和西坡存在显著负相关 $(p<0.05$,
图2)。在坡向梯度上随着红砂根系分叉数的增加， 根系分支角度均呈减小趋势, 表明红砂根系分叉数 和分支角度之间存在权衡关系。北坡和南坡红砂根 系分叉数和分支角度回归方程的SMA斜率逐渐减 小 $(p<0.05)$, 而东坡、西坡甘肃臭草根系分叉数和 分支角度回归方程的SMA斜率之间无显著差异 $(p>$ $0.05)$, 各个坡向的SMA斜率的绝对值显著小于 $1(p$ $<0.05)$, 表明根系分叉数的增长速率大于根系分支 角度的生长速率, 红砂根系具有较强的分支能力, 有利于发挥根系吸收代谢及固土蓄水能力作用。

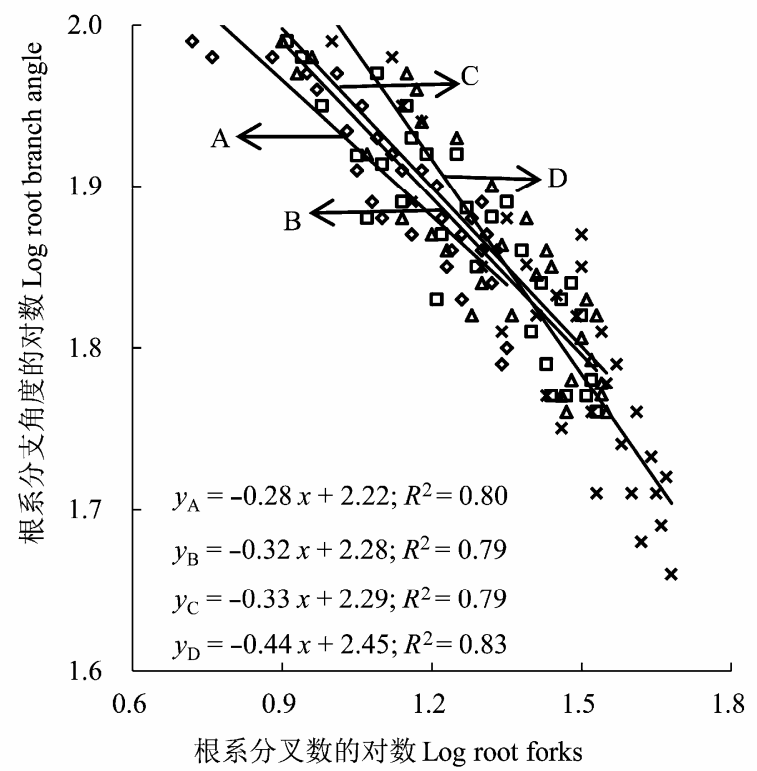

图2 不同坡向红砂根系分叉数和分支角度的关系。A, 南 坡; B, 西坡; C, 东坡; D, 北坡。

Fig. 2 The relationship between root forks and branch angle of Reaumuria songarica in different aspects of slopes. A, South slope; B, West slope; C, East slope; D, North slope.

\section{3 不同坡向红砂的生长特征}

不同坡向梯度分布的红砂生长特征差异均显著 $(p<0.05$, 表1)。随着坡向由南坡转向西坡、东坡和 北坡, 红砂种群的根冠比呈逐渐减小趋势, 从南坡 到北坡减小了 $48.08 \%$; 密度、高度、根深和比根长 呈相反的变化趋势逐渐增加, 从南坡到北坡分别增 大了 1.5 倍、0.53倍、1.8倍和0.57倍。这些生长特征 值在东坡和西坡之间无显著差异 $(p>0.05)$ 。

\section{4 不同坡向红砂草地群落及土壤水分特征}

不同坡向红砂草地群落和土壤水分特征存在差 异 $(p<0.05$, 表2)。随着坡向由南坡向西坡、东坡和 
表1 红砂生长特征随坡向梯度的变化(平均值土标准误差)

Table 1 Growth characteristics of Reaumuria songarica along an aspect gradient (mean $\pm S E$ )

\begin{tabular}{|c|c|c|c|c|c|}
\hline $\begin{array}{l}\text { 坡向 } \\
\text { Aspect }\end{array}$ & $\begin{array}{c}\text { 密度 } \\
\text { Density }\left(\text { 株· } \mathrm{m}^{-2}\right)\end{array}$ & $\begin{array}{c}\text { 高度 } \\
\text { Height }(\mathrm{cm})\end{array}$ & $\begin{array}{c}\text { 根冠比 } \\
\text { Root-shoot ratio }\end{array}$ & $\begin{array}{c}\text { 根深 } \\
\text { Root depth (cm) }\end{array}$ & $\begin{array}{c}\text { 比根长 } \\
\text { Specific root length }\left(\mathrm{cm} \cdot \mathrm{g}^{-1}\right)\end{array}$ \\
\hline 南 South & $2 \pm 0.08^{\mathrm{c}}$ & $15.60 \pm 0.52^{\mathrm{c}}$ & $0.52 \pm 0.02^{\mathrm{a}}$ & $16.92 \pm 0.86^{\mathrm{c}}$ & $22.27 \pm 1.34^{\mathrm{c}}$ \\
\hline 西 West & $3 \pm 0.12^{\mathrm{b}}$ & $19.26 \pm 0.96^{\mathrm{b}}$ & $0.46 \pm 0.03^{\mathrm{b}}$ & $29.35 \pm 1.58^{\mathrm{b}}$ & $26.43 \pm 1.56^{\mathrm{b}}$ \\
\hline 东 East & $3 \pm 0.11^{b}$ & $18.42 \pm 0.73^{\mathrm{b}}$ & $0.43 \pm 0.02^{\mathrm{b}}$ & $31.28 \pm 1.64^{\mathrm{b}}$ & $27.18 \pm 1.38^{\mathrm{b}}$ \\
\hline 北 North & $5 \pm 0.21^{\mathrm{a}}$ & $23.85 \pm 1.43^{\mathrm{a}}$ & $0.27 \pm 0.01^{\mathrm{c}}$ & $47.76 \pm 2.48^{\mathrm{a}}$ & $35.06 \pm 1.40^{\mathrm{a}}$ \\
\hline
\end{tabular}

同一列不同小写字母表示坡向间差异显著 $(p<0.05)$ 。

Different lowercase letters indicate significant differences among slope aspects $(p<0.05)$.

表2 不同坡向红砂草地群落的主要特征指标(平均值土标准误差)

Table 2 The major characteristics of Reaumuria songarica in different aspects of slopes (mean $\pm S E$ )

\begin{tabular}{|c|c|c|c|c|c|c|}
\hline \multirow{2}{*}{$\begin{array}{l}\text { 坡向 } \\
\text { Aspect }\end{array}$} & \multicolumn{5}{|c|}{ 群落特征 Community properties } & \multirow{2}{*}{$\begin{array}{c}\text { 土壤含水量 } \\
\text { Soil moisture } \\
\text { content (\%) }\end{array}$} \\
\hline & $\begin{array}{c}\text { 盖度 } \\
\text { Coverage (\%) } \\
\end{array}$ & $\begin{array}{c}\text { 密度 Density } \\
\left(\text { 株· } \mathrm{m}^{-2}\right) \\
\end{array}$ & $\begin{array}{c}\text { 高度 } \\
\text { Height }(\mathrm{cm}) \\
\end{array}$ & $\begin{array}{c}\text { 地上生物量 } \\
\text { Aboveground biomass }\left(\mathrm{g} \cdot \mathrm{m}^{-2}\right)\end{array}$ & $\begin{array}{c}\text { 地下生物量 } \\
\text { Belowground biomass }\left(\mathrm{g} \cdot \mathrm{m}^{-2}\right) \\
\end{array}$ & \\
\hline 南 South & $18 \pm 1.26^{\mathrm{c}}$ & $8 \pm 0.33^{\mathrm{d}}$ & $19.00 \pm 1.14^{\mathrm{c}}$ & $54.99 \pm 4.07^{\mathrm{C}}$ & $38.69 \pm 1.97^{\mathrm{c}}$ & $6.10 \pm 0.43^{\mathrm{c}}$ \\
\hline 西 West & $34 \pm 1.70^{b}$ & $15 \pm 0.69^{c}$ & $21.70 \pm 1.08^{b}$ & $75.81 \pm 5.23^{b}$ & $53.46 \pm 2.87^{\mathrm{b}}$ & $7.60 \pm 0.46^{\mathrm{b}}$ \\
\hline 东 East & $36 \pm 1.44^{\mathrm{b}}$ & $17 \pm 0.77^{\mathrm{b}}$ & $21.32 \pm 1.06^{\mathrm{b}}$ & $77.48 \pm 5.39^{\mathrm{b}}$ & $54.87 \pm 2.91^{\mathrm{b}}$ & $8.20 \pm 0.33^{b}$ \\
\hline 北 North & $65 \pm 2.60^{\mathrm{a}}$ & $25 \pm 1.21^{\mathrm{a}}$ & $24.80 \pm 0.99^{\mathrm{a}}$ & $91.75 \pm 4.77^{\mathrm{a}}$ & $74.76 \pm 3.88^{\mathrm{a}}$ & $11.50 \pm 0.58^{\mathrm{a}}$ \\
\hline
\end{tabular}

同列不同小写字母表示坡向间差异显著 $(p<0.05)$ 。

Different lowercase letters indicate significant differences among slope aspects $(p<0.05)$.

北坡转变, 土壤含水量呈递增趋势, 由南坡的 $6.1 \%$ 增加到北坡的 $11.5 \%$ ，土壤水分在南坡具有最小值， 北坡具有最大值; 从南坡到北坡，草地群落的盖 度、密度、高度、地上生物量和地下生物量呈递增 趋势, 群落盖度增加了2.61倍, 群落密度增加了 2.13 倍, 群落高度增加了 $31 \%$, 地上生物量增加了 $67 \%$, 地下生物量增加了 $93 \%$, 且在东坡和西坡之间无显 著差异 $(p>0.05)$ 。表明在 4 个坡向中, 北坡生境条件 最适合植株的生长。

\section{3 讨论}

植物在长期的进化过程中, 通过生理和发育调 节形成与环境相适应的表型特征，进而具备了提高 植物水分、养分等资源利用效率的功能(李西良等, 2014)。在异质性生境中, 植物根系面对水分和养分 吸收、运移和存储的环境压迫, 其分叉数和分支角 度可能会发生适应性变化, 并通过物质能量吸收、 固着格局的调整反作用于植被生态系统的稳定和种 群更新机制, 体现了植物根系进行空间探索以适应 环境胁迫的能力(Zhao et al., 2013)。本研究发现, 随 着坡向由南坡向西坡、东坡和北坡的转变, 红砂根 系分支角度逐渐减小, 而根系分叉数呈相反的变化 趋势(图1), 在有限的资源环境中, 红砂分配给根系 分叉数和分支角度资源间存在着“此消彼长”的权衡
关系。坡向梯度上红砂根系分叉数和分支角度关系 的差异性是植物根系构建的资源配置模式对生境异 质性的适应对策。

植物外部形态具有高度的环境可塑性特征，在 长期生长发育的过程中, 生境差异性使其主要构件 采取了不同的生态对策，能够协调各功能性状间的 资源分配模式以规避环境风险(史元春等, 2015)。植 物根系构型构建与植物自身根系碳投入和土壤水分 养分的收益权衡相契合，是植物提高自身资源获取 能力的一个重要策略(杨小林等, 2008)。研究区位于 祁连山与河西走廊过渡带的荒漠草原区, 山地南坡 的植物生存环境比较严酷, 红砂的生物量水平低 (表1, 表2), 为了提高自身的生存和繁衍能力, 红砂 将更多的同化产物分配给地下根系, 着力构建强大 的物质吸收和存储系统，从而限制了地上生物量的 分配比例(表1), 形成了相对较小的、有助于降低植 株总体蒸腾耗水量的枝叶性状体系(表3)。南坡植被 稀疏(表2)、大气温度较高, 结构松散的沙土毛细管 吸收作用力弱。在土壤含水量偏低(表2)和无地下水 补给的条件下, 荒漠植物往往需要较大集水面积才 能满足植株最低水平的生理耗水需求, 红砂选择了 增加根系分支角度、减小分叉数的根系构型构建模 式, 原因如下: 1)红砂属于浅根系植物, 绝大部分根 系与地面平行伸展, 形成相对较大的根系分支角度 
表3 不同坡向红砂叶与枝性状(平均值土标准误差)

Table 3 Leaf and twig traits of Reaumuria songarica on different aspects (mean $\pm S E$ )

\begin{tabular}{lccc}
\hline $\begin{array}{l}\text { 坡向 } \\
\text { Aspect }\end{array}$ & $\begin{array}{c}\text { 单叶面积 } \\
\text { Individual leaf area } \\
\left(\mathrm{mm}^{2}\right)\end{array}$ & $\begin{array}{c}\text { 枝长度 } \\
\text { Twig length } \\
(\mathrm{cm})\end{array}$ & $\begin{array}{c}\text { 枝条数 } \\
\text { Twig number }\end{array}$ \\
\hline 南 South & $0.66 \pm 0.03^{\mathrm{c}}$ & $1.91 \pm 0.06^{\mathrm{c}}$ & $7 \pm 0.41^{\mathrm{c}}$ \\
西 West & $0.87 \pm 0.05^{\mathrm{b}}$ & $2.74 \pm 0.15^{\mathrm{b}}$ & $10 \pm 0.61^{\mathrm{b}}$ \\
东 East & $0.90 \pm 0.05^{\mathrm{b}}$ & $3.02 \pm 0.17^{\mathrm{b}}$ & $11 \pm 0.64^{\mathrm{b}}$ \\
北 North & $1.14 \pm 0.06^{\mathrm{a}}$ & $4.38 \pm 0.24^{\mathrm{a}}$ & $16 \pm 1.03^{\mathrm{a}}$ \\
\hline
\end{tabular}

同列不同小写字母表示坡向间差异显著 $(p<0.05)$ 。

Different lowercase letters indicate significant differences among slope aspects $(p<0.05)$.

(图1), 更有利于侧根趋向于水平分布、扩大根系的 有效受养空间，同样单位(长度)的根系拥有的吸水 土壤体积可能较大, 从而具有比同一生境中相邻植 物更强的水资源竞争能力, 可以获得更多的生存机 会(蒋礼学和李彦，2008)。这符合相关学者“分支角 度越大, 根系越趋向于水平分布, 向根更广的范围 扩展以寻求资源”的研究结论(黄晶晶, 2013)。2)植物 根系处于干旱或贫瘦的土壤环境中时, 会采取降低 分支强度, 保证自身的生存和生长的策略(杜建会 等, 2014)。生长在南坡的红砂减小其根系分叉数的 根系构型(图1), 在一定程度上降低了根系内部的交 叠重复, 可以避免细根间资源空间的竞争, 从而提 高根系对营养物质的吸收效率来加快对土壤资源的 利用, 以最佳的收益/代价关系适应贫痊的资源环 境, 与相关学者得出一致的结论, 即 “当植物根系处 于干旱或贫㾉的土壤环境中时, 会采取降低分支强 度, 减少根系分叉数的策略以降低根系内部的交叠 重复, 避免细根营养物质的竞争” (单立山等, 2012; 杜建会等, 2014)。因此, 分布于南坡的红砂根系分 叉数和分支角度间呈极显著负相关关系 $(p<0.01$, 图2), 实现了光合产物在构件水平的优化配置。

植物构件的资源分配是与栖息环境相对应的种 群特征的反映方式, 它反映了种群特定的生态适应 策略(张茜等, 2014)。根系构型会对周围环境产生适 应性的改变, 表现出不一样的适应特性(Oppelt et al., 2005)。相对于南坡, 山地北坡草地群落的盖度、 密度均较大, 红砂在群落中没有高度优势(表1, 表 2), 相对拥挤的群落环境使植物面临着严重的邻体 干扰, 红砂将较多的生物量分配给地上枝叶以利于 植株获得高度优势, 增强枝叶的捕光能力, 无形中 限制了分配给根系的生物量比例(表1)。在根冠比较 低的情况下, 红砂需要将有限的资源用于构建根系
的吸收面积，增强根系的“受食”能力(董鸣，1996), 以最大限度保证植株在生境竞争中占据优势, 红砂 选择了增加根系分叉数、减小分支角度的根系构型。 原因如下: 1)在土壤含水量相对较高的北坡(表2), 红 砂以根系分叉数增加速度大于分支角度减小速度的 资源配置模式(图2), 通过增大根系分叉数(图1), 有 效增加了根系分支能力和单位土体中根系的拥挤 度, 构建了密集的根系网络系统, 降低了根系传输 系统的碳需求量, 实现了单位根系土壤拓展体积较 小状态下的植株生存的水分供给需求, 这与单立山 等(2013)对红砂和白刺(Nitraria tangutorum)、杨小 林等 (2008) 对塔克拉玛干柽柳 (Tamarix taklamakanensis)的研究结果相一致。2)植物根系在深 层土壤的分布有利于其吸收利用深层土壤水分, 促 进植株的生长发育(席海洋等, 2011)。北坡群落密度 高(表2)、植物之间拥挤度大, 种内和种间容易造成根 系重叠竞争, 空间上无法满足大范围根系的构型塑 造。红砂采取缩小根系水平范围, 将根系分支角度 减小, 扩大根系在深层土壤中的垂直分布(表1), 避 免与群落中其他植株根系的剧烈竞争。同时红砂植 物通过增大比根长提高对养分和水分的利用效率来 加快对土壤资源的利用(表1), 提高自身的竞争力以 维持生存。因此, 红砂根系分叉数和分支角度间呈 极显著负相关关系 $(p<0.01$, 图2), 即以资源权衡分 配机制进化响应诸多竞争压力, 维持植物生长的水 分条件, 从而有利于生物多样性的群落结构, 这符 合相关学者“分叉数较大的植物能够迅速占据大量 土壤空间快速生长, 适宜生长在土壤资源丰富的环 境中”的结论(周艳松和王立群, 2011; 孙浩燕等, 2014)。

植物个体间的相互作用实际上是可获得性资源 的有限性导致的构件水平的竞争(马维玲等, 2010), 根系是植物营养物质摄取、运输、贮存和合成场所, 也是寻受新的生境和营养的繁殖器官(黄晶晶等, 2013), 影响植株个体的生长、发育和植物种群的生 活史对策(Dannowski \& Block, 2005)。东坡和西坡属 于半阴和半阳坡, 是植被类型的交错带, 植被多样 性较高, 群落组成较为复杂, 草地群落密度分别为 17 株 $\cdot \mathrm{m}^{-2}$ 和 15 株 $\cdot \mathrm{m}^{-2}$, 盖度为 $36 \%$ 和 $34 \%$, 高度为 $21.32 \mathrm{~cm}$ 和 $21.70 \mathrm{~cm}$, 都介于南坡和北坡之间, 植物 之间的邻体干扰较大。为了增强资源竞争能力和生 境适合度, 红砂选择了折中的地上、地下生物量配 
置模式，兼顾了地上植株空间拓展和地下根系水 分、养分吸收传输的物质需求。受地下生物量有限 性的约束, 在权衡根系吸水面积和吸水效率等生理 生态功能的基础上, 红砂选择了既有利于提高根系 分布密度, 又能增强根系空间拓展能力的根系分叉 数和分支角度优化配置模式。因此生长在东坡和西 坡植株的二者的相关性仅达到显著水平 $(p<0.05$, 图1), 是根系分支角度由大到小、根系分叉数由小 到大转变的区域。

\section{4 结论}

根系分叉数和分支角度关系不仅是植物个体发育 过程的表现，也体现植物在特定环境的构型塑造和对 特定生境的适应性。本研究发现, 生境对根系分叉数 和分支角度关系有显著的影响, 不同坡向中红砂根 系功能性状存在差异。生长在南坡的红砂选择了增 加根系分支角度、减小分叉数的扩散型根系构型, 是其在逆境中扩展根系的分布范围及降低细根营养 物质的竞争的生长策略; 北坡的红砂通过增大根系 分叉数、减小分支角度, 趋向于构建紧缩型的根系 构型, 是其提高根系吸收利用效率和减弱荒漠植物 “大根系”吹余消耗养分的弊端的生活史对策。这种 结果较好地验证了植物通过调整表型可塑性的自我 补偿、更新策略。本文仅从坡向角度分析了根系分 叉数-分支角度的变化特征, 它们的关系可能还受 到坡度等其他微地形因子以及物种遗传特性的影 响, 还需要进一步的实验验证。

基金项目 国家自然科学基金(41461013和91125014)和甘肃省生态学重点学科。

\section{参考文献}

Bauhus J, Khanna PK, Menden N (2000). Aboveground and belowground interactions in mixed plantations of Eucalyptus globulus and Acacia mearnsii. Canadian Journal of Forest Research, 30, 1886-1894.

Cantón Y, Del Barrio G, Solé-Benet A, Lázaro R (2004). Topographic controls on the spatial distribution of ground cover in the Tabernas badlands of SE Spain. Catena, 55, 341-365.

Chang XL, Lü SH, Feng ZY, Ye SX (2015). Impact of topography on the spatial distribution pattern of net primary productivity in a meadow. Acta Ecologica Sinica, 35, 3339-3348. (in Chinese with English abstract) [常学礼, 吕世海, 冯朝阳, 叶生星 (2015). 地形对草甸草原植被 生产力分布格局的影响. 生态学报, 35, 3339-3348.]
Chen Y, Xu X, Zhang DR, Wei Y (2006). Correlations between vegetation distribution and topographical factors in the northwest of Longmen Mountain, Sichuan Province. Chinese Journal of Ecology, 25, 1052-1055. (in Chinese with English abstract) [陈瑶, 胥晓, 张德然, 魏勇 (2006). 四 川龙门山西北部植被分布与地形因子的相关性. 生态 学杂志, 25, 1052-1055.]

Chen YT, Xu ZZ (2014). Review on research of leaf economics spectrum. Chinese Journal of Plant Ecology, 38, 11351153. (in Chinese with English abstract) [陈荣婷, 许振柱 (2014). 植物叶经济谱的研究进展. 植物生态学报, 38, 1135-1153.]

Dannowski M, Block A (2005). Fractal geometry and root system structures of heterogeneous plant communities. Plant and Soil, 272, 61-76.

Dong M (1996). Clonal growth in plants in relation to resource heterogeneity: Foraging behavior. Acta Botanica Sinica, 38, 828-835. (in Chinese with English abstract) [董鸣 (1996). 资源异质性环境中的植物克隆生长: 受食行为. 植物学报, 38, 828-835.]

Druille M, Cabello MN, García Parisi PA, Golluscio RA, Omacini M (2015). Glyphosate vulnerability explains changes in root-symbionts propagules viability in pampean grasslands. Agriculture, Ecosystems and Environment, 202, 48-55.

Du JH, Liu AL, Dong YX, Hu MY, Liang J, Li W (2014). Architectural characteristics of roots in typical coastal psammophytes of South China. Chinese Journal of Plant Ecology, 38, 888-895. (in Chinese with English abstract) [杜建会, 刘安隆, 董玉祥, 胡绵友, 梁杰, 李薇 (2014). 华南海岸典型沙生植物根系构型特征. 植物生态学报, 38, 888-895.]

Falster DS, Warton DI, Wright IJ (2006). User's Guide to SMATR: Standardised Major Axis Tests \& Routines Version 2.0. http://www.bio.mq.edu.au/ecology/SMATR/. Cited: 2014-11-20.

Glimskär A (2000). Estimates of root system topology of five plant species grown at steady-state nutrition. Plant and Soil, 227, 249-256.

Harvey PH, Pagel MD (1991). The Comparative Method in Evolutionary Biology. Oxford University Press, Oxford, UK.

Hou ZJ, Zhao CZ, Li Y, Zhang Q, Ma XL (2014). Trade-off between height and branch numbers in Stellera chamaejasme on slopes of different aspects in a degraded alpine grassland. Chinese Journal of Plant Ecology, 38, 281-288. (in Chinese with English abstract) [侯兆疆, 赵成章, 李 钰, 张茜, 马小丽 (2014). 不同坡向高寒退化草地狼毒 株高和枝条数的权衡关系. 植物生态学报, 38, 281-288.]

Huang JJ (2013). Cloning Root System Distribution and 
Architecture of Populus euphratica in Ejina Oasis. Master degree dissertation, Beijing Forestry University, Beijing. (in Chinese with English abstract) [黄晶晶 (2013). 额济 纳荒漠绿洲胡杨根系特征的研究. 硕士学位论文, 北京 林业大学, 北京.]

Huang JJ, Jing JL, Cao DC, Zhang N, Li JW, Xia YG, Lü S (2013). Cloning root system distribution and architecture of different forest age Populus euphratica in Ejina Oasis. Acta Ecologica Sinica, 33, 4331-4342. (in Chinese with English abstract) [黄晶晶, 井家林, 曹德昌, 张楠, 李景 文, 夏延国, 吕爽 (2013). 不同林龄胡杨克隆繁殖根系 分布特征及其构型. 生态学报, 33, 4331-4342.]

Ji WP, Wang JJ, Zhao XC, Lai LM, Wang YJ, Ma YJ, Zhao CQ, Zheng YR (2013). Fine root production and turnover of Alhagi sparsifolia community in arid area of Xinjiang, Northwest China. Chinese Journal of Ecology, 32, 2635-2640. (in Chinese with English abstract) [冀卫萍, 王健健, 赵学春, 来利明, 王永吉, 马远见, 赵春强, 郑 元润 (2013). 干旱区骆驼刺群落细根生产与周转. 生态 学杂志, 32, 2635-2640.]

Jiang LX, Li Y (2008). Comparison on architecture characteristics of root systems and leaf traits for three desert shrubs adapted to arid habitat. Journal of Desert Research, 28, 1118-1124. (in Chinese with English abstract) [蒋礼学, 李彦 (2008). 三种荒漠灌木根系的构形特征与叶性因 子对干旱生境的适应性比较. 中国沙漠, 28, 11181124.]

Kong XP, Zhang ML, de Smet I, Ding ZJ (2014). Designer crops: Optimal root system architecture for nutrient acquisition. Trends in Biotechnology, 32, 597-598.

Li XL, Hou XY, Wu XH, Sa RL, Ji L, Chen HJ, Liu ZY, Ding $Y$ (2014). Plastic responses of stem and leaf functional traits in Leymus chinensis to long-term grazing in a meadow steppe. Chinese Journal of Plant Ecology, 38, 440-451. (in Chinese with English abstract) [李西良, 侯 向阳, 吴新宏, 萨茹拉, 纪否, 陈海军, 刘志英, 丁勇 (2014). 草甸草原羊草茎叶功能性状对长期过度放牧的 可塑性响应. 植物生态学报, 38, 440-451.]

Ma WL, Shi PL, Li WH, He YT, Zhang XZ, Shen ZX, Chai SY (2010). Changes in individual plant traits and biomass allocation in alpine meadow with elevation variation on the Qinghai-Tibetan Plateau. Science China: Life Sciences, 53, 1142-1151. [马维玲, 石培礼, 李文华, 何永涛, 张宪洲, 沈振西 (2010). 青藏高原高寒草甸植株性状和生物量 分配的海拔梯度变异. 中国科学: 生命科学, 40, 533543.]

Ma XM, Xi L, Xiong SP, Yang J (2006). Dynamic changes of morphological parameters of tobacco root in field. Chinese Journal of Applied Ecology, 17, 373-376. (in Chinese with English abstract) [马新明, 席否, 熊淑萍, 杨娟 (2006).
大田期烟草根系构型参数的动态变化. 应用生态学报, 17, 373-376.]

Malamy JE (2005). Intrinsic and environmental response pathways that regulate root system architecture. Plant, Cell \& Environment, 28, 67-77.

Oppelt AL, Kurth W, Dzierzon H, Jentschke G, Godbold DL (2000). Structure and fractal dimensions of root systems of four co-occurring fruit tree species from Botswana. Annals of Forest Science, 57, 463-475.

Oppelt AL, Kurth W, Godbold DL (2001). Topology, scaling relations and Leonardo's rule in root systems from African tree species. Tree Physiology, 21, 117-128.

Oppelt AL, Kurth W, Godbold DL (2005). Contrasting rooting patterns of some arid-zone fruit tree species from Botswana-II. Coarse root distribution. Agroforestry Systems, 64, 13-24.

Shan LS, Li Y, Dong QL, Geng DM (2012). Ecological adaptation of Reaumuria soongorica root system architecture to arid environment. Journal of Desert Research, 32, 1283-1290. (in Chinese with English abstract) [单立山, 李毅, 董秋莲, 耿东梅 (2012). 红砂根系构型对干旱的 生态适应. 中国沙漠, 32, 1283-1290.]

Shan LS, Li Y, Ren W, Su SP, Dong QL, Geng DM (2013). Root architecture of two desert plants in central Hexi Corridor of Northwest China. Chinese Journal of Applied Ecology, 24, 25-31. (in Chinese with English abstract) [单 立山, 李毅, 任伟, 苏世平, 董秋莲, 耿东梅 (2013). 河 西走廊中部两种荒漠植物根系构型特征. 应用生态学 报, 24, 25-31.]

Shi YC, Zhao CZ, Song QH, Du J, Chen J, Wang JW (2015). Slope-related variations in twig and leaf traits of Robinia pseudoacacia in the northern mountains of Lanzhou. Chinese Journal of Plant Ecology, 39, 362-370. (in Chinese with English abstract) [史元春, 赵成章, 宋清华, 杜晶, 陈静, 王继伟 (2015). 兰州北山刺槐枝叶性状的坡向差 异性. 植物生态学报, 39, 362-370.]

Sun HY, Li XK, Ren T, Cong RH, Lu JW (2014). Effects of fertilizer in shallow soils on growth and distribution of rice roots at seedling stage. Scientia Agricultura Sinica, 47, 2476-2484. (in Chinese with English abstract) [孙浩燕, 李小坤, 任涛, 丛日环, 鲁剑巍 (2014). 浅层施肥对水 稻苗期根系生长及分布的影响. 中国农业科学, 47, 2476-2484.]

Tang GA, Li FY, Liu XJ (2010). Tutorial of Digital Elevation Model. 2nd edn. Science Press, Beijing. 149. (in Chinese) [汤国安, 李发源, 刘学军 (2010). 数字高程模型教程. 第二版. 科学出版社, 北京. 149.]

Tracy SR, Black CR, Roberts JA, Dodd IC, Mooney SJ (2015). Using X-ray Computed Tomography to explore the role of abscisic acid in moderating the impact of soil compaction 
on root system architecture. Environmental and Experimental Botany, 110, 11-18.

Warton DI, Wright IJ, Falster DS, Westoby M (2006). Bivariate line-fitting methods for allometry. Biological Reviews, 81, 259-291.

Xi HY, Feng Q, Si JH, Chang ZQ, Su YH, Guo R (2011). Spatio-temporal characteristics of soil in Ejina Oasis. Journal of Desert Research, 31, 68-75. (in Chinese with English abstract) [席海洋, 冯起, 司建华, 常宗强, 苏永 红, 郭瑞 (2011). 额济纳绿洲不同植被覆盖下土壤特性 的时空变化. 中国沙漠, 31, 68-75].

Xiong DC, Huang JX, Yang ZJ, Lu ZL, Cheng GS, Yang YS (2012). Fine root architecture and morphology among different branch orders of six subtropical tree species. Acta Ecologica Sinica, 32, 1888-1897. (in Chinese with English abstract) [熊德成, 黄锦学, 杨智杰, 卢正立, 陈光 水, 杨玉盛 (2012). 亚热带6种树种细根序级结构和形 态特征. 生态学报, 32, 1888-1897.]

Yang XL, Zhang XM, Li YL, Li SC, Sun HL (2008). Analysis of root architecture and root adaptive strategy in the Taklimakan desert area of China. Journal of Plant Ecology (Chinese Version), 32, 1268-1276. (in Chinese with English abstract) [杨小林, 张希明, 李义玲, 李绍才, 孙海 龙 (2008). 塔克拉玛干沙漠腹地 3 种植物根系构型及其 生境适应策略. 植物生态学报, 32, 1268-1276.]

Zeng FJ, Guo HF, Liu B, Zeng J, Xing WJ, Zhang XL (2010). Characteristics of biomass allocation and root distribution of Tamarix ramosissima Ledeb. and Alhagi sparsifolia Shap. seedlings. Arid Land Geography, 33, 59-64. (in Chinese with English abstract) [曾凡江, 郭海峰. 刘波, 曾杰, 邢文娟, 张晓蕾 (2010). 多枝柽柳和疏叶骆驼刺 幼苗生物量分配及根系分布特征. 干旱区地理, 33, 59-64.]

Zhang Q, Zhao CZ, Dong XG, Ma XL, Hou ZJ, Li Y (2014). Trade-off between the biomass and number of flowers in Stellera chamaejasme along an elevation gradient in a degraded alpine grassland. Chinese Journal of Plant Ecology, 38, 452-459. (in Chinese with English abstract) [张 茜, 赵成章, 董小刚, 马小丽, 侯兆疆, 李钰 (2014). 高 寒退化草地狼毒种群不同海拔花大小-数量的权衡关系. 植物生态学报, 38, 452-459.]

Zhao CZ, Sheng YP, Ren H, Gao FY, Zhang J (2013). A study on the root competitive pattern of annual pasture in mixed grassland in alpine region. Acta Ecologica Sinica, 33, 145-149.

Zhou YS, Wang LQ (2011). Ecological adaptation of root architecture to grassland degradation in Potentilla acaulis. Chinese Journal of Plant Ecology, 35, 490-499. (in Chinese with English abstract) [周艳松, 王立群 (2011). 星 毛委陵菜根系构型对草原退化的生态适应. 植物生态 学报, 35, 490-499.]

责任编委: 何维明 责任编辑: 李 敏 